\title{
Resolutividade no tratamento de larva migrans por equipe com visão ampliada de saúde: relato de caso
}

\section{Resoluteness at the treatment of larva migrans by amind open vision health team: case report}

Pedro Henrique Borges Reis*, Alex Pereira Ramos, Raimundo Marcial de Brito Neto, Laís Franco Duarte, Maria Cristina Almeida de Souza, Edsneider Rocha Pires de Souza

Como citar esse artigo. Reis, P.H.B.; Ramos, A.P.; Neto, R.M.B.; Duarte, L.F. de Souza, M.C.A.; de Souza, E.R.P. Resolutividade no tratamento de larva migransporequipe com visão ampliada de saúde: relato de caso. Revista de Saúde. 2019 Jan./Jun.; 10 (1): 27-31.

\section{Resumo}

A larva migrans cutânea, também conhecida como bicho geográfico, é uma infecção cutânea causada por nematódeos. A resolutividade do tratamento de larva migrans é otimizada quando o indivíduo é cuidado por equipes que compreendem a relevância da interface do meio ambiente ao processo saúde-doença. O objetivo é relatar neste trabalho o caso de uma paciente portadora de larva migranscutânea, cuidada pela equipe de uma Unidade Estratégia Saúde da Família no município de Vassouras/RJ. A visão ampliada de saúde, embasada nos princípios da Ecologia Médica, foi um diferencial para a resolutividade do caso.

Palavras-chave: Larva migranscutanea; Dermatologia; Medicina; Atenção Primária à Saúde.

\begin{abstract}
Cutaneous larva migrans, also known as geographic critter, is a cutaneous infection caused by nematodes. The resoluteness of larva migrans treatment is optimized when the individual is cared for by teams who understand the relevance of the interface of the environment to the health-disease process. The objective is to report in this work the case of a patient with cutaneous larva migrans, cared for by the staff of a Family Health Unit in the city of Vassouras / RJ. The broad vision of health, based on the principles of Medical Ecology, was a differential for the resolution of the case.

Keywords: Intraperitoneal bladder rupture; Mild abdominal trauma.
\end{abstract}

\section{Introdução}

A larva migranscutânea, também conhecida como bicho geográfico, é uma infecção cutânea causada por nematódeos do gênero Ancylostoma,mais frequentemente pelas espécies Ancylostomabraziliense e Ancylostomacaninum, parasitas que vivem no intestino de animais domésticos, como cães e gatos ${ }^{1,2,3,4,5}$.

Ao defecar na terra ou areia, os ovos eliminados nas fezes eclodem dando origem as larvas.A contaminação do homem se dá quando há um contato da sua pele com o solo, principalmente quando se anda descalço sobre terreno arenoso contaminado com fezes ${ }^{1,2,4}$.A prevalência dessa infecção é maior em crianças e a contaminação geralmente se dá via membros inferiores, principalmente pés, pois entram em contato com o solo. Contaminações no tronco ou nos membros superiores não são comuns $\mathbf{s}^{1,2,3,4,6}$.

Clinicamente, no local da superfície corporal por onde as larvas penetram surge uma lesão eritematopapulosa, que se expande formando um túnel tortuoso e avermelhado,cuja extremidade migrante apresenta-se mais ativa, enquanto a área terminal começa a entrar em regressão, gerando intenso prurido. As lesões podem ser únicas ou múltiplas. Casos reacionais intensos chegam a apresentar vesículas e bolhas. $\mathrm{O}$ ato de coçar as lesões pode levar a infecções secundárias ${ }^{1,2,4}$.

O diagnósticoda larva migrans cutânea é

Afiliação dos autores: Pró-Reitoria de Ciências Médicas, Universidade de Vassouras, Vassouras, Rio de Janeiro, Brasil.

*Email de correpondência: alexramosmed@gmail.com 
basicamente clínico, baseado na ectoscopia por meio da verificação de lesões típicas na pele. Relevante também é a queixa do portador sobre o prurido persistente, além da observação de condições ambientais deficientes, visto que se trata de uma patologia dependente de vetores. $\mathrm{O}$ tratamento baseia-se na administração de anti-helmínticos orais e/ou pomadas. Às vezes tornase necessário o uso de antibióticos sistêmicos para o tratamento das infecções secundárias ${ }^{1,2,3,4,5,6}$.

Muitos dos agravos em saúde se relacionam a questões ambientais, uma vez que as alterações no meio ambiente interferem na saúde dos indivíduos, de forma que meio ambiente e saúde são indissociáveis. Assim, para a resolutividade do cuidado em saúde é imprescindível que os profissionais se atentem para os determinantes ambientais do processo saúde-doença ${ }^{1,6}$.

O objetivo do presente estudo é relatar um caso em que a resolutividade do cuidado à portadora de larva migrans foi otimizada por intermédio da promoção de ações diferenciadas por uma equipe dotada de visão ampliada de saúde, com destaque para as orientações quanto às questões ambientais. A resolutividade do tratamento de larva migran pode ser maximizada quando o indivíduo é cuidado por equipes que compreendem a relevância da ecologia médica e da interface meio ambiente/processo saúde-doença, haja vista a imprescindibilidade de orientações de educação em saúde sobre medidas preventivas, essenciais ao autocuidado em saúde.

\section{Relato de caso}

Paciente R.S.R., do lar, gênero feminino, 49 anos de idade, cor parda, sem comorbidades prévias, procurou a Unidade Estratégia Saúde da Família (ESF) "Doutor
Mário Branco", na periferia do município de Vassouras/ RJ, queixando-se de "coceira na barriga". Na anamnese, como queixa principal, relatou o aparecimento de lesão avermelhada, acompanhada de moderado prurido, cerca de 6 dias anteriores à consulta (Figura 1).

Relatou que havia, sem sucesso, aplicado compressa morna no local. Decorridos 7 dias, observou que o prurido aumentou de intensidade e ocorreu a formação de uma lesão hiperemiada mais extensa e tortuosa, justificando a procura por cuidados na ESF. Negou frequentar parques e praças ou outros locais onde a presença de areia é usual. Relatou ter convivência com animais domésticos, principalmente com gato de estimação, que dorme diariamente em sua cama.

À ectoscopia e ao exame físico, o médico constatou bom estado geral, pressão arterial 130x80 mmHg, lesão eritematosa serpiginosa com a extremidade migrante ativa a distal descamativa em flanco esquerdo. Sem outras alterações significativas de registro (Figura 2).

Foi então diagnosticada a presença de "larva migrans cutânea" devido aos achados clínicos, característicos da patologia, apesar da idade da paciente e do local da lesão não serem usuais. Como fatores diretamente relacionados, citam-se o convívio com o gato de estimação e o fato da paciente morar em uma área onde transitam muitos animais de rua, que em sua maioria não recebem cuidados básicos por meio de políticas públicas de saúde. A conduta terapêutica adotada foi a prescrição de Albendazol $400 \mathrm{mg}$, dois comprimidos em dose única, com repetição da mesma dosagem após sete dias. Topicamente, prescreveu-se o antiparasitário Tiabendazol creme $15 \mathrm{mg} / \mathrm{g}$, para ser aplicado três vezes ao dia na área lesionada, por cinco dias. Ressalta-se que ambos os fármacos integram a

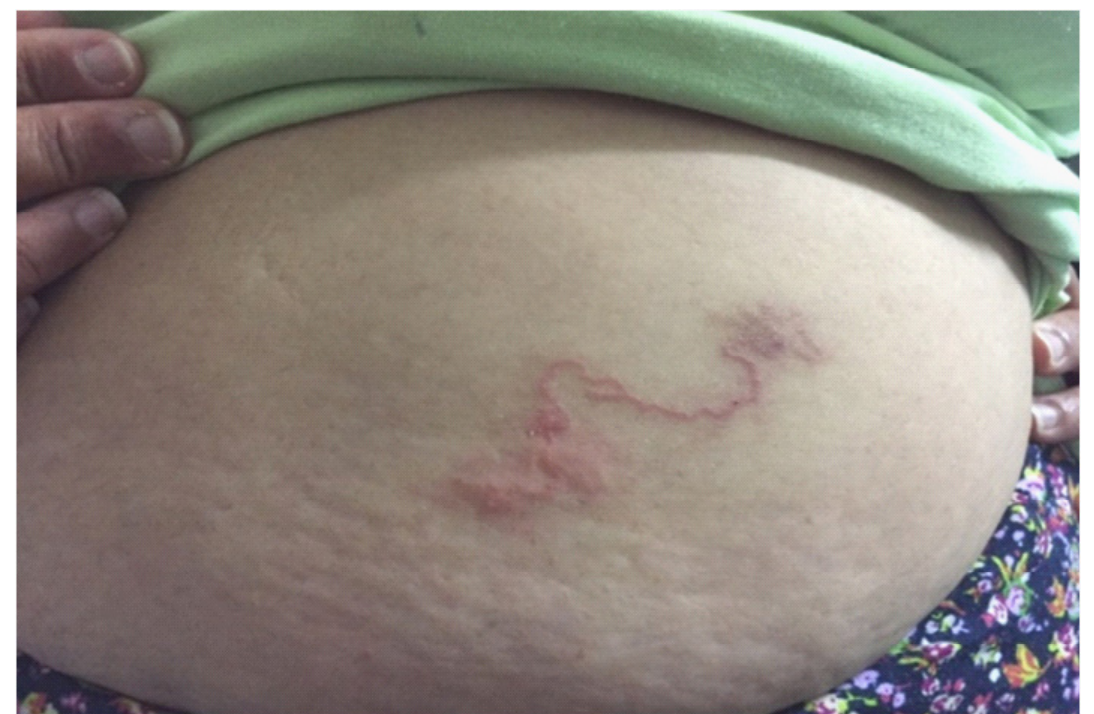

Figura 1. Lesão inicial localizada em região mesogástrica, a qual se observa lesão serpiginosa e eritematosa com apresentação de mácula de limites imprecisos em região distal. 


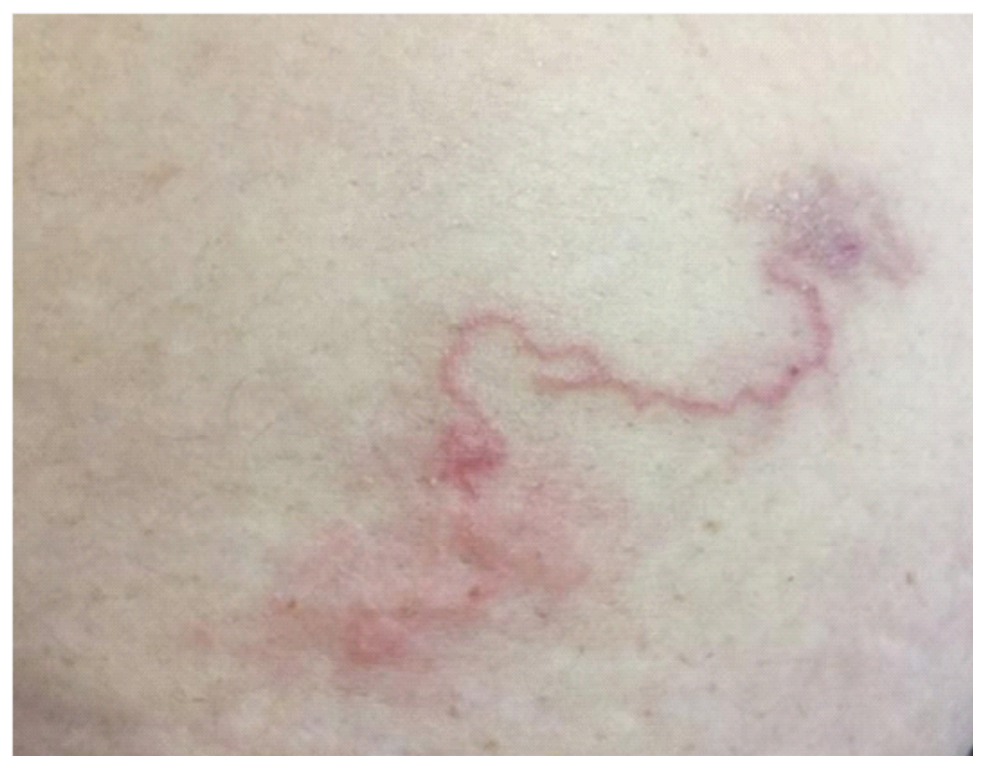

Figura 2. Aspecto macroscópico clínico da lesão, onde nota-se a uniformidade da coloração da lesão, sendo a mais arroxeada compatível com uma lesão mais antiga quando comparada à lesão mais inferior em forma de mácula.

Relação Municipal de Medicamentos do Município (REMUME) e foram fornecidos gratuitamente à usuária da ESF.

A paciente foi orientada sobre a importância de não permitir a presença de animais em seu dormitório, principalmente em sua cama, evitando assim, um novo contágio. Foi também informada acerca da importância de vermifugar o animal de estimação, cuja operacionalização poderia ser solicitada ao médico veterinário do Núcleo de Apoio à Saúde da Família (Nasf$\mathrm{AB}$ ) ou do Centro de Vigilância em Saúde do município. Evitar andar descalço em áreas onde transitam animais foi uma das orientações enfatizadas. Uma consulta para reavaliação do caso foi agendada no prazo de sete dias. Não houve necessidade de solicitação de exame complementar nem referenciamento ao especialista da média complexidade, haja vista que o diagnóstico da dermatozoonose foi realizado pelo médico da ESF.

A fim de atender ao princípio da promoção da saúde, durante o período de intervalo entre as consultas programadas para a paciente, a equipe da ESF realizou uma Visita Domiciliar (VD) à residência da usuária com intuito de verificar se as orientações estavam sendo seguidas, bem como observar a vizinhança, na busca pró-ativa de casos semelhantes. No momento da consulta de reavaliação, a resolutividade do caso foi constatada (Figura 3).

A paciente teve um excelente prognóstico, pois se trata de uma doença autolimitada e o risco de infecção secundária pelo ato de coçar foi reduzido pelo adequado tratamento instituído.

\section{Discussão}

A larva migrans cutânea é uma patologia comum em regiões tropicais, entre as quais, o Brasil. Contudo, seu diagnóstico pode não ser realizado por profissionais de saúde, especialmente os que atuam na Atenção Primária em Saúde, ocasionando o encaminhamento do portador ao serviço do nível secundário da Rede de Atenção à Saúde, principalmente quando a lesão se encontra em fase inicial, cujos sinais clínicos característicos ainda não são tão evidentes, dificultando o diagnóstico ${ }^{1,3,4,5,6}$.

No caso relatado neste trabalho, o diagnóstico pôde ser estabelecido com relativa segurança, mesmo não se tratando de um caso tão típico, principalmente devido ao cuidado prestado por uma equipe de saúde ciente da interface entre meio ambiente e processo saúde-doença, característico de profissionais com visão ampliada de saúde ${ }^{7}$.

$\mathrm{O}$ que difere esse caso de outros são, principalmente, a idade da paciente e o local da lesão. Quanto ao gênero da portadora, não representa fator de risco ou proteção ao surgimento da lesão. A faixa etária mais afetada são as crianças $^{1,2,4,5}$, que se justifica pela maior exposição a locais públicos, onde transitam animais portadores de helmintos. Cabe ainda salientar que as lesões, na maioria dos casos, surgem em regiões desprotegidas, que entram em contato com o meio onde está presente a larva, tais como pés, pernas, nádegas e mãos ${ }^{1,2,3,4,6}$.

A anamnese foi de grande importância, pois corroborou o que foi visto no exame físico e na ectoscopia. $\mathrm{O}$ fato de a paciente dormir com o gato serviu 


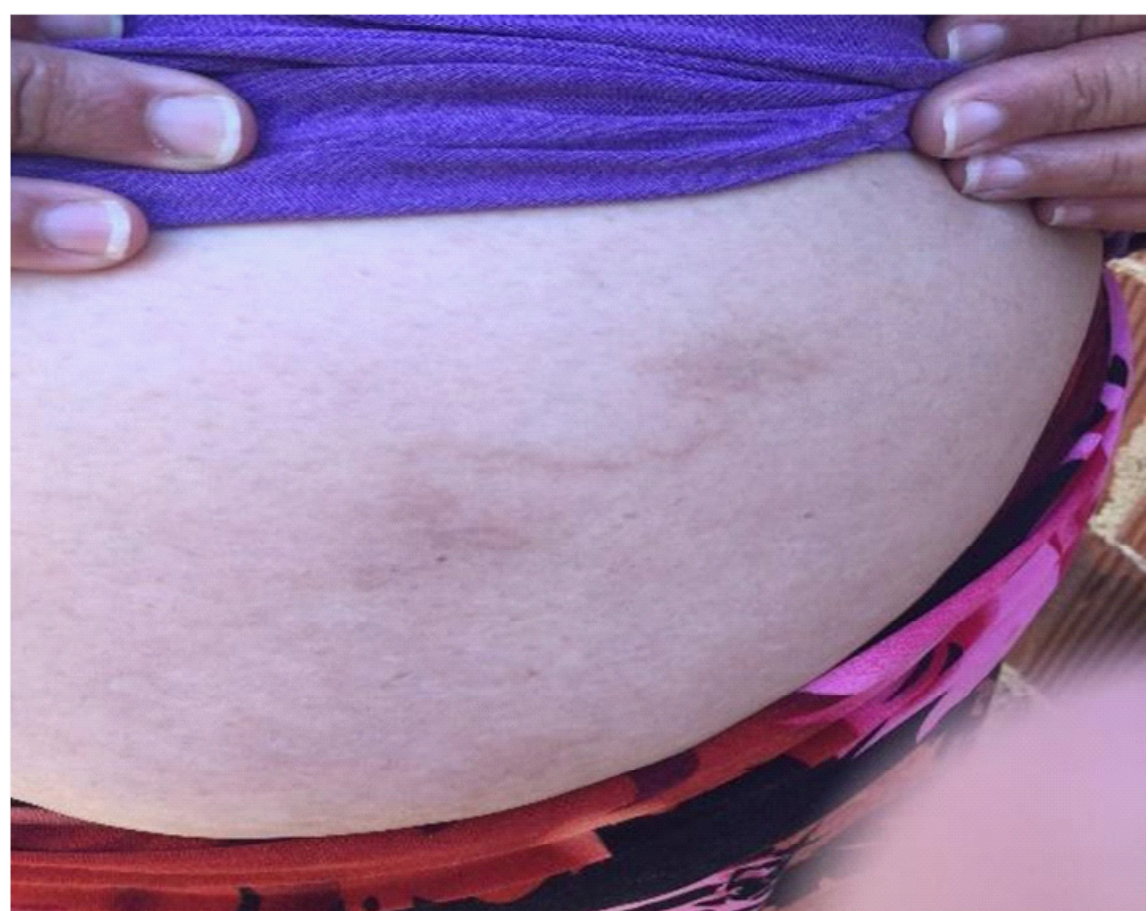

Figura 3. Lesão após reavaliação pela equipe, percebendo-se melhora clínica do aspecto macroscópico, bem como referida pela paciente.

para esclarecer sobre a fonte de infecção e mostrou o motivo da presença de lesão em local incomum, pois o mesmo dormia em sua cama e tinha contato direto com seu abdome. Também permitiu compreender o porquê de a idade não ser a mais frequente relatada nesse tipo de patologia, visto que a paciente não frequentava parques públicos nem tinha contato direto com areia, situações na qual a faixa etária infantil está mais exposta.

É possível perceber a imprescindibilidade da anamnese para um possível diagnóstico de larva migrans. Contudo, isso só foi possível devido ao conhecimento do território adscrito à unidade de saúde pela equipe da ESF, que constatou a presença de animais, principalmente cães e gatos sem donos e consequentemente sem a adequada assistência. No local há áreas com areia, onde fezes de animais são encontradas com relativa frequência, haja vista ser uma zona rural onde nem todas as ruas são asfaltadas, o que favorece a disseminação das larvas. Nota-se que a população ainda carece de informação visto que muitos moradores andam descalços nas ruas e crianças brincam desprotegidas em relação às fezes na areia ${ }^{1,2,3,4,5,6}$.

O tratamento realizado foi condizente com o apresentado na literatura científica ${ }^{1,2,3,4,5,6}$. Tanto o Albendazol como o Tiabendazol são anti-helmínticos com espectro contra o agente etiológico da larva migrans. Alguns autores, contudo, afirmam que é possível tratar a lesão apenas com uso de drogas tópicas ${ }^{1,4}$. No caso relatado, o tiabendazol também foi indicado, além do fármaco de uso oral, para agilizar a regressão do desconforto, em razão da significativa extensão da lesão. Adicionalmente, o fármaco oral auxilia no tratamento contra outros parasitas frequentes na região, que tem um saneamento básico insatisfatório. Cabe ainda ressaltar que apesar de existirem outras opções de medicamentos, foram prescritos Albendazol e Tiabendazol, pois são medicamentos integrantes da REMUME e foram disponibilizados gratuitamente à usuária. As orientações do médico em relação à patologia e ao contágio foram de fundamental importância, pois não bastam tratar o sintoma e as consequência, é preciso erradicar a causa e empoderar a população acerca de medidas preventivas por meio de ações de educação em saúde $^{7,8}$.

Diante do tema e do cenário apresentado, o presente relato mostra a importância para acadêmicos e profissionais de saúde sobre a necessidade de se abordarem as patologias considerando o papel do meio ambiente no processo saúde-doença enfatizando a relevância da Ecologia Médica no cotidiano do processo de trabalho dos profissionais de saúde ${ }^{7,8,9,10}$.

Pôde-se perceber, nesse caso, que quando o médico detém conhecimento no âmbito da ecologia médica e a aplica em seu cotidiano, é possível prever certos acontecimentos, prevenir patologias e até mesmo otimizar a adoção de medidas preventivas, além de evitar custos onerosos decorrentes do agravamento da lesão e de infecções secundárias ${ }^{7,8}$.

A resolutividade do caso foi maximizada pelo conhecimento da região de atuação por parte da equipe médica, o que facilitou o direcionamento do pensamento clínico, ou seja, "previu a patologia". O conhecimento 
pela equipe da ESF de que animais potencialmente contaminados transitavam no local, em uma área sem pavimentação, com areia e saneamento pouco eficiente, favoreceu a hipótese diagnóstica de larva migrans cutânea, mesmo sendo um caso atípico. Esse fato, somado às características clínicas da lesão, corroborou para elaborar corretamente o diagnóstico, não havendo necessidade de encaminhamento para o especialista, o que foi vantajoso para a paciente, que não necessitou prolongar seu sofrimento, e para o gestor de saúde visto que é muito menos oneroso aos cofres públicos resolver um caso na atenção básica. Cabe ressaltar que as informações compartilhadas pela equipe com a paciente, por meio das atividades de educação em saúde, contribuirão para a prevenção de novos casos.

Caso a equipe da Unidade ESF em questão não possuísse a visão ampliada em saúde, muito provavelmente a paciente ainda estaria sem diagnóstico, sem a resolução do seu incômodo e esperando uma vaga para consulta com especialista, retardando a resolutividade do caso. Esse é apenas um caso, que serve para ilustrar como o médico que possui uma visão abrangente de saúde pode proporcionar muito mais benefícios do que aqueles que ainda têm a visão hegemônica e hospitalocêntrica de saúde. O profissional com a capacidade de interpretar e intervir no meio ambiente é capaz não só de fazer o diagnóstico e tratar, mas também de prevenir novos casos.

A importância da equipe de saúde de conhecer o ambiente onde vivem as pessoas cuja saúde está sob sua responsabilidade fica evidente para a adequação da intervenção nos determinantes do processo saúdedoença ${ }^{11}$. Os pontos positivos da ecologia médica já estão sendo notados por aqueles mais estudiosos e atentos a esta interface, justificando o fato de escolas médicas do país incluírem em seus currículos conteúdos programáticos relacionados ao tema, formando médicos com uma visão ampliada de saúde ${ }^{12}$.

\section{Conclusão}

A resolutividade do cuidado prestado ao portador de larva migrans cutânea foi otimizada por intermédio da promoção de ações diferenciadas por uma equipe dotada de visão abrangente de saúde, com destaque para as orientações quanto às questões ambientais. Ressaltase que as ações de promoção e de educação em saúde pela equipe foram fundamentais para a resolução do caso, evidenciando o fato de que equipes cientes da interface meio ambiente-saúde pode fazer a diferença na resolutividade de casos da doença aqui relatada.
2. Macias VC, Carvalho R, Chaveiro A, Cardoso J. Larva Migrans cutânea a propósito de um caso clínico. Revista SPDV 2013; 71 .

3. Santarem VA, Giuffrida R, Zanin GA. Larva migrans cutânea: ocorrência de casos humanos e identificação de larvas de Ancylostomaspp em parque público do município de Taciba, São Paulo. Rev. Soc. Bras. Med. Trop. 2004 37(2):179-81.

4. Alves C, Proença V. Larva Migrans cutânea - um caso de apresentação típica no viajante. Revista Portuguesa Medicina Geral e Familiar. 2012; 28:136-8.

5. Kerri SP, Richard GL, Amanda NW, Noreen W, David H. Cutaneous Larva Migrans. The Lancet Infectiousdiseases 2011; 377:1948.

6. Alves C, Proença V. Larva migrans cutânea - Um caso de apresentação típica no viajante; Rev. Port. Med. Geral Fam 2012; 28:136-8.

7. Lima AD. Ecologia Médica: uma Visão Holística no Contexto das Enfermidades Humanas; Rev. Brasileira de educação médica 2014, 38(2): 165-72.

8. Azeredo CM, Cotta RMM, Schott M, Maia TM, Marques ES. Avaliação das condições de habitação e saneamento: a importância da visita domiciliar no contexto do Programa de Saúde da Família. Ciênc. saúde coletiva. 2007, 12(3):743-53.

9. ZöllnerIanni, AM, Dias Quitério LA. A questão ambiental urbana no programa de saúde da família: avaliação da estratégia ambiental numa política pública de saúde. Ambiente \& Sociedade 2006, 9:169-80.

10. Patrício KP, Oliveira TS, Ribeiro JTR, Medeiros TM, Cruvinel MCFP, Miguel MM et al. Meio ambiente e saúde no Programa PET-Saúde: interfaces na atenção básica. Rev. bras. educ. med. 2011, 35(3):341-9.

11. Schmidt RACA. questão ambiental na promoção da saúde: uma oportunidade de ação multiprofissional sobre doenças emergentes. Physis, 2007, 17(2):373-92.

12. Souza MCA, Teixeira JCD, Almeida Júnior EHR, Costa EMA, Gonçalves SJC, Côrtes Júnior JCS, Mendonça MA. Relato de Inovação Pedagógica na Abordagem da Ecologia Médica. Rev. bras. educ. med. 2015, 39(4):597601

\section{Referências}

